\title{
Phytobiotic Effect of Anacardium occidentale L. Leaves Powder on Performance, Carcass Traits, and Intestinal Characteristics in Broilers
}

\section{-Author(s)}

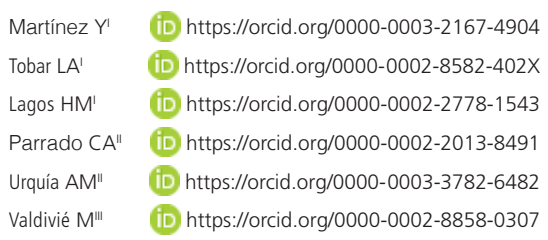

Departamento de Ciencia y Producción Agropecuaria, Escuela Agrícola Panamericana Zamorano, Valle del Yeguare, San Antonio de Oriente, 93, Honduras.

Departamento de Ambiente y Desarrollo, Escuela Agrícola Panamericana Zamorano, Valle del Yeguare, San Antonio de Oriente, 93, Honduras.

III Centro Nacional para la Producción de Animales de Laboratorio, Santiago de las Vegas, Rancho Boyeros, La Habana, Cuba.

\section{Mail Address}

Corresponding author e-mail address Yordan Martínez

Departamento de Ciencia y Producción Agropecuaria, Escuela Agrícola

Panamericana, Valle de Yeguare, San Antonio de Oriente, Francisco Morazán 96, Honduras.

Phone: +504 94422496

Email: ymartinez@zamorano.edu

\section{- Keywords}

Broiler; cashew; productive indicator; breast characteristics; organ

\section{ABSTRACT}

In order to evaluate the phytobiotic effect of cashew (Anacardium occidentale L.) leaves powder (CLP) on growth performance, carcass traits, lymphoid organ weights and cecal lactic-acid bacteria in broilers, a total of 720 unsexed broilers of the Ross $308 \AA$ genetic line were distributed according to a completely randomized design with three experimental treatments, five repetitions and 48 chickens per repetitions. The experimental treatments consisted of a basal diet (DB; TO) and DB + supplementation with 0.50 (T1) and $0.75 \%$ (T2) of CLP. At 32 days, the body weight, feed intake and feed conversion ratio were not modified $(p>0.05)$ by the experimental groups; however, T1 increased $(p<0.05)$ the viability compared to T0. Additionally, T2 improved $(p<0.05)$ the carcass and leg yields, although without significant changes $(p>0.05)$ for the other edible portions. Moreover, this natural product (A. occidentale) increased $(p<0.05)$ the ash content and the range of the red tone and decreased $(p<0.05)$ the $L^{*}$ in the breast, although moisture, fat, $\mathrm{pH}$, and $b *$ were not affected by the experimental diets $(p>0.05)$. Similarly, T1 favored $(p<0.05)$ the growth of green bacterial colonies with a white halo, and both treatments with CLP the total cecal acid-lactic bacteria. No significant changes were observed $(p>0.05)$ in the relative weight of the immune organs (thymus, bursa of Fabricius, and spleen). Dietary supplementation with cashew leaves powder enhanced the viability of the batch $(0.5 \%)$, some edible portions $(0.75 \%)$, the breast pigmentation, and the cecal beneficial bacteria count in broilers.

\section{INTRODUCTION}

The World Health Organization-WHO (2018) as a consequence of the use of antibiotics and their impact on the environment has determined that the frequency of resistance among bacterial pathogens is increasing worldwide and is considered as one of the biggest threats to health. Although, the inappropriate use of antibiotics in human medicine is considered the main driver of this phenomenon, the excessive use of antibiotics in livestock farming contributes greatly to increasing this threat (ECDC, 2015). As a result, the improper use of antibiotics in livestock activity is currently severely criticized by international health authorities and the media (WHO, 2018), therefore has generated interest in different areas to improve management practices in different productive sectors. Thus, the researchers' current premise is to obtain natural alternatives to decrease the indiscriminate use of antibiotics and improve performance in birds (Aroche et al., 2018).

Consequently, in this post-antibiotic stage, phytonutrients, phytobiotics, or additives have gained increasing interest due to their important biological activities, including anti-inflammatory, antioxidant, antimicrobial, and immunomodulatory functions (Windisch et al., 2007). 
Phytobiotic Effect of Anacardium Occidentale L. Leaves Powder on Performance, Carcass Traits, and Intestinal Characteristics in Broilers

\section{Preparation of the phytobiotic from the cashew leaves}

The cashew leaves were collected randomly from 10 trees of approximately 10 years of age in the periurban areas of the municipality of Palestina - Patuca in the department of Olancho, Honduras. For the collection of the leaves, the diversity in size and structure were considered, as well as the optimal classification of the leaves, identified in the Agricultural Science and Production Department, Pan-American Agricultural School, Honduras. The leaves were deposited and stored in a fiber bag to avoid the increase in humidity due to transpiration during transportation to the preparation area (Aroche et al., 2018).

Distilled water was used to wash the leaves and remove impurities. Subsequently, the layer of leaves $(1-2 \mathrm{~cm})$ was placed on a dry wide surface, protected with paper, and left to dry naturally inside for 5 days according to the methodology of Martínez et al. (2012 c). Once dry, the leaves were transported to the Food Analysis laboratory, Pan-American Agricultural School, Honduras and grounded with a blade mill to a grain size of $1 \mathrm{~mm}$ (Martínez et al., 2012 b). The dry matter (DM), crude protein $(C P)$ and crude fiber were determined in triplicate (AOAC, 2006). The concentrations of calcium (Ca), sodium ( $\mathrm{Na})$, manganese $(\mathrm{Mn})$, zinc $(\mathrm{Zn})$, copper (Co) and phosphorous ( $\mathrm{P})$ were determined in triplicate by inductively coupled plasma-optical emission spectrometry (ICP-OES, Perkin Elmer Optima 3200RL) (Table 1). Furthermore, in previous works we determined that the leaves of this plant have a significant concentration of flavonoids (mainly cyanidin 3-O-xylosyl-rutinoside), tannins, beta-sitosterol, coumarins, reducing sugars and anthocyanidins (Martínez et al., 2012 c,d).

\section{Experimental design, animals, and treat- ments}

A total of 720 unsexed broilers of the Ross $308 \AA$ genetic line were distributed according to a completely

Table 1 - Chemical composition of Cashew leaves powder.

\begin{tabular}{|c|c|c|c|}
\hline Chemical composition & Means & Standard deviation & Coefficient of variation \\
\hline Dry matter (\%) & 88.65 & 0.507 & 0.571 \\
\hline Crude protein (\%) & 10.12 & 0.346 & 3.418 \\
\hline Crude fiber (\%) & 18.00 & 0.256 & 1.422 \\
\hline $\mathrm{Ca}(\%)$ & 0.35 & 0.011 & 3.142 \\
\hline$P(\%)$ & 0.25 & 0.010 & 4.00 \\
\hline $\mathrm{Na}(\%)$ & 0.22 & 0.010 & 4.545 \\
\hline $\mathrm{Zn}(\mathrm{mg} / \mathrm{kg})$ & 28.00 & 0.500 & 1.785 \\
\hline $\mathrm{Co}(\mathrm{mg} / \mathrm{kg})$ & 7.98 & 0.150 & 1.879 \\
\hline $\mathrm{Mn}(\mathrm{mg} / \mathrm{kg})$ & 500.00 & 3.605 & 0.721 \\
\hline
\end{tabular}


randomized design in three experimental treatments, five repetitions and 48 chickens per repetitions. The experimental treatments consisted of a basal diet (DB; T0) and DB + supplementation with 0.50 (T1) and $0.75 \%$ (T2) of cashew leaves powder. Three (threephase) feeding phases were used: 0-10 days (Starter);
11-24 days (Grower) and 25-32 days (Finisher). Basal diets according to the nutritional requirements of Ross 308 ${ }^{\circledR}$ (Aviagen, 2019) were formulated (Table 2). For dietary supplementation levels with $C L P$, the recommendations of Martínez et al. (2012 a); and Aroche et al. (2018) were used.

Table 2 - Ingredients and nutritional contributions of the broilers diet.

\begin{tabular}{|c|c|c|c|}
\hline Ingredients (\%) & Starter (1-10 days) & Grower (11-24 days) & Finisher (25-32 days) \\
\hline Cornmel (CP, 8.30\%) & 47.36 & 51.33 & 53.77 \\
\hline Soymeal (CP, $48.00 \%)$ & 39.67 & 35.13 & 31.70 \\
\hline Mineral and vitamin premix & 0.50 & 0.50 & 0.50 \\
\hline Sodium chloride & 0.50 & 0.50 & 0.50 \\
\hline Palm oil & 8.20 & 9.19 & 10.38 \\
\hline Choline & 0.08 & 0.05 & 0.05 \\
\hline DL-Methionine & 0.37 & 0.33 & 0.32 \\
\hline L-Threonine & 0.10 & 0.06 & 0.05 \\
\hline L-Lysine & 0.27 & 0.23 & 0.22 \\
\hline Calcium carbonate & 1.10 & 1.05 & 0.99 \\
\hline Biofos $®$ & 1.63 & 1.41 & 1.30 \\
\hline Mycotoxin sequestrants & 0.12 & 0.12 & 0.12 \\
\hline Enzymes & 0.05 & 0.05 & 0.05 \\
\hline Coccidiostat & 0.05 & 0.05 & 0.05 \\
\hline \multicolumn{4}{|l|}{ Nutritional contributions (\%) } \\
\hline metabolizable energy (kcal/kg) & 3000 & 3100 & 3200 \\
\hline Crude protein & 23.43 & 21.50 & 20.00 \\
\hline Crude fiber & 3.28 & 3.22 & 3.15 \\
\hline Ashes & 6.35 & 5.91 & 5.60 \\
\hline $\mathrm{Ca}$ & 0.96 & 0.87 & 0.81 \\
\hline $\mathrm{P}$ available & 0.48 & 0.43 & 0.40 \\
\hline Lysine & 1.28 & 0.87 & 0.83 \\
\hline Methionine + cystine & 0.95 & 0.78 & 0.57 \\
\hline Threonine & 0.86 & 0.77 & 0.71 \\
\hline Valine & 0.89 & 0.72 & 0.67 \\
\hline Isoleucine & 0.86 & 0.78 & 0.73 \\
\hline Leucine & 1.71 & 1.15 & 1.06 \\
\hline Histidine & 0.65 & 0.62 & 0.60 \\
\hline Arginine & 1.30 & 1.18 & 1.09 \\
\hline Tryptophan & 0.23 & 0.21 & 0.19 \\
\hline Phenylalanine & 0.93 & 0.88 & 0.84 \\
\hline
\end{tabular}

'Each kg contains: vitamin A, 13,500 Ul; vitamin D3, 3,375 Ul; vitamin E, 34 mg; B2, 6 mg; pantothenic acid, 16 mg; nicotinic acid, 56 mg; Cu, 2,000 mg; folic acid, 1.13 mg; vitamin B12, 34 mg; Mn, 72 mg; Zn, 48 mg.

\section{Experimental conditions}

Each replication consisted of a pen with a deep wood chip bed and 11 birds $/ \mathrm{m}^{2}$. Feed and water were offered ad libitum in hopper feeders and nipple waterers, respectively. The temperature and ventilation inside the ship were controlled by gas brooders, curtain management and fans. The barn was disinfected according to environmental quality standards of Poultry Research and Education Center Protocol, 24 hours before the chicks entered the experimental area, this was disinfected with quaternary ammonium (5\%). No medications or therapeutic veterinary care were used throughout the experimental stage. The birds were vaccinated against Newcastle, Gumboro diseases, and infectious bronchitis on the first day.

\section{Growth performance}

In each feeding phase (starter, grower, and finisher) the indicators of the productive performance of the broilers were determined. Viability was determined by the total count of live animals from the population size for each repetition at the start of the experiment. The initial and final body weight (BW) of each stage was performed for each animal with a Mettler Toledo® IND226 industrial scale (China) with an accuracy of \pm $1.00 \mathrm{~g}$. The feed intake (FI) was determined daily through 
Phytobiotic Effect of Anacardium Occidentale L. Leaves Powder on Performance, Carcass Traits, and Intestinal Characteristics in Broilers the offer and reject method. The feed conversion ratio (FRC) was calculated by the relationship among the amount of feed eaten and the gain of $1 \mathrm{~g}$ of body weight.

\section{Carcass traits and lymphoid organ weights}

At 32 days of age, 10 male broilers per treatment were sacrificed by the bleeding method through the jugular vein, the birds were fasted for six hours. Initially, the broilers were weighed before slaughter on the Truweigh Blaze digital scale BL-100-01-BK (China) with an accuracy of $\pm 0.1 \mathrm{~g}$. Afterwards, the carcass, the edible viscera (liver, heart, and gizzard), breast, liver, abdominal fat, bursa of Fabricius, thymus and spleen were weighed.

The analysis of the chemical composition of the breast was performed five times in the Food Analysis Laboratory of the Zamorano University. The skinless breasts were thawed and ground to a paste with a homogenizing blender, except for the colorimetry analysis, which used a small portion of the entire muscle. Afterwards, $1 \mathrm{~g}$ of ground meat was weighed and $10 \mathrm{ml}$ of distilled water were added, the sample was homogenized for two minutes with a vortex and with a Bantex model 300 A digital potentiometer, calibrated with buffer solutions ( $\mathrm{pH} 4$ to 7), and then the meat $\mathrm{pH}$ was determined.

In addition, the color test was determined with a sphere spectrophotometer Minolta CR-400/410 chromameter (Konica Minolta Sensing Inc., Osaka Japan). For the latter, samples were placed inside the equipment and each muscle was sampled twice. Chromatic coordinates $L^{*}$ (luminosity), a* (red index) and $b^{*}$ (yellow index) were evaluated. Additionally, in the samples the content of moisture, fat, ash, and protein were prescribed, according to the methodology described by AOAC (2006).

\section{pH and cecal lactic acid bacteria}

At the time of slaughter, five left cecum and five right cecum were taken for each treatment. In the left cecum, $\mathrm{pH}$ was determined using an Oakton ${ }^{\circledR}$ model pH 700 (USA) digital potentiometer, calibrated using buffer solutions $(\mathrm{pH} 1.68,4.01,7.00,10.01$, and 12.45).

Besides, the left cecum of five birds/treatment was taken, and the mucosa was scraped with a scalpel for microbiological culture. Each sample's cecal content was placed in a sterile tube; weight was recorded and diluted with Butterfield's phosphate-buffered dilution water to a 1:9 ratio (w:v). Diluted cecal contents were homogenized, and serial dilutions (1/10) were made from it until dilution $10^{\wedge} 5$. Aliquots of $0.1 \mathrm{ml}$ of each dilution were spread plated on the surface of MRS agar (Neogen Acumedia, Mich.) supplemented with methylene blue $(0.016 \mathrm{~g} / 1000 \mathrm{ml})$ at $37{ }^{\circ} \mathrm{C}$ with a $\mathrm{pH}$ of 5.6 for 48 hours in anaerobiosis (Gas Pak system, BBL, Cockeysville, USA). Counts of lactic acid bacteria were reported as Log CFU/g by colonies' morphology on MRS + MB agar. Gram stain and catalase activity were tested on each type of colonies reported (Molina et al., 2019). The microbiological tests were performed in the Food Microbiology Laboratory of the Zamorano University.

\section{Statistical analysis}

Data was processed by simple classification analysis of variance (ANOVA) in a completely randomized design. Prior to this, the normality of the data was verified by the Kolmogorov Smirnov test and for the uniformity of variance, the Bartlett test was used. In some cases, the Duncan's test was used to determine the differences between means. Viability was determined by comparison of proportions. All analyzes were carried out according to the SPSS statistical software version 21.0 .

\section{RESULTS AND DISCUSSION}

Table 3 shows the growth performance of broiler when CLP is used as a dietary supplement. At 10 days of age, T2 increased $(p<0.05)$ body weight and feed intake compared to T0, although no changes were found for the viability and feed conversion ratio among treatments $(p>0.05)$. In the grower period (11-24 days), T1 showed the highest percentages for viability in relation to T0 $(p<0.05)$, the other indicators did not change $(p>0.05)$ because of the natural product ( $A$. occidentale), the same happened in the other productive stages (25-32 days and 0-32 days). Likewise, the experimental groups with CLP increased $(p<0.05)$ the viability in the finisher stage (25-32 days), and throughout the production stage (0-32 days) T1 showed the best result for this productive indicator $(p<0.05)$.

The objective of the experimental work was to determine whether the use of this natural product (cashew) with high in dry matter and protein (Table 1) in broilers had the same positive effects previously found in laying hens and pullets (Martínez et al., 2012 a; Martínez et al., 2013), considering that the broiler has a more susceptible digestive system due to rapid growth. From 11-32 days, T1 demonstrated a direct 
Table 3 - Effect of dietary supplementation with cashew leaves powder on growth performance of broilers.

\begin{tabular}{|c|c|c|c|c|c|}
\hline \multirow[b]{2}{*}{ Items } & \multicolumn{3}{|c|}{ Experimental treatments } & \multirow[b]{2}{*}{ SEM \pm} & \multirow[b]{2}{*}{$p$ value } \\
\hline & TO & $\mathrm{T} 1$ & $\mathrm{~T} 2$ & & \\
\hline \multicolumn{6}{|c|}{ Starter (0-10 days) } \\
\hline IBW (g) & 45.38 & 44.93 & 44.73 & 0.511 & 0.666 \\
\hline FBW (g) & $243.60^{b}$ & $255.15^{\mathrm{ab}}$ & $266.48^{a}$ & 4.826 & 0.026 \\
\hline Viability (\%) & 97.40 & 97.92 & 97.40 & 1.111 & 0.968 \\
\hline Fl (g/bird) & $235.05^{b}$ & $257.16^{a}$ & $260.40^{a}$ & 4.349 & 0.005 \\
\hline $\mathrm{FCR}(\mathrm{kg} / \mathrm{kg})$ & 1.19 & 1.22 & 1.18 & 0.027 & 0.458 \\
\hline \multicolumn{6}{|c|}{ Grower (11-24 days) } \\
\hline FBW (g) & 1219.03 & 1239.88 & 1206.18 & 28.279 & 0.706 \\
\hline Viability (\%) & $96.79^{b}$ & $100.00^{\mathrm{a}}$ & $98.40^{\mathrm{ab}}$ & 0.917 & 0.005 \\
\hline $\mathrm{FI}$ (g/bird) & 1100.18 & 1082.03 & 1087.35 & 32.415 & 0.921 \\
\hline $\mathrm{FCR}(\mathrm{kg} / \mathrm{kg})$ & 1.13 & 1.11 & 1.63 & 0.055 & 0.760 \\
\hline \multicolumn{6}{|c|}{ Finisher (25-32 days) } \\
\hline FBW (g) & 1833.48 & 1892.10 & 1857.13 & 52.758 & 0.739 \\
\hline Viability (\%) & $97.79^{b}$ & $100.00^{\mathrm{a}}$ & $100.00^{\mathrm{a}}$ & 0.062 & 0.032 \\
\hline $\mathrm{Fl}$ (g/bird) & 973.70 & 1030.80 & 1005.23 & 36.622 & 0.564 \\
\hline $\mathrm{FCR}(\mathrm{kg} / \mathrm{kg})$ & 1.59 & 1.60 & 1.61 & 0.124 & 0.991 \\
\hline \multicolumn{6}{|c|}{ Starter-Finisher (0-32 days) } \\
\hline Viability (\%) & $92.19^{b}$ & $97.92^{\mathrm{a}}$ & $95.83^{\mathrm{ab}}$ & 1.525 & 0.003 \\
\hline $\mathrm{Fl}$ (g/bird) & 2308.93 & 2369.98 & 2352.98 & 63.067 & 0.784 \\
\hline $\mathrm{FCR}(\mathrm{kg} / \mathrm{kg})$ & 1.29 & 1.29 & 1.30 & 0.033 & 0.935 \\
\hline
\end{tabular}

a,bMeans within the same row with different superscript differ significantly $(p<0.05)$.

TO: basal diet (BD); BD+0.50\% of cashew leaves powder (T1); BD+0.75\% of cashew leaves powder (T2). IBW: initial body weight; FBW: final body weight; Fl: feed intake; FCR: feed conversion ratio.

effect on viability, this could be attributed to the fact that CLP has a high content of essential minerals (Table 1), as well as beneficial secondary metabolites such as coumarins, flavonoids, triterpenes, anthocyanins, phenols, and saponins that in small concentrations have antimicrobial, anti-inflammatory, and antioxidant effects, which benefit the animal response (Martínez et al., 2012 c).

In this sense, Pawar et al. (2000); da SilveiraVasconcelos et al. (2015) and Awakan et al. (2018) reported that the leaves of this medicinal plant are rich in the organic compound oleamide (9-octadecenamide), and become responsible for its anti-inflammatory activity in animal models. Other studies reported similar results in viability when they used CLP as part of a mixed medicinal powder in broilers (Aroche et al., 2018), which clearly shows that this natural product (up to $0.75 \%$ ) does not cause symptoms related to anti-nutritional factors, because an excess of secondary metabolites (mainly tannins) inhibits the absorption of nutrients, which can cause metabolic disorders and negative effects for the production of broilers (Savón et al., 2007). Conversely, Huang et al. (2017) informed that small concentrations of tannins on broiler diets could be used as an alternative to in-feed antibiotics due to its anti-inflammatory and antimicrobial effect. Thus, phytobiotic products represent a promising non- antibiotic tool that improves the intestinal health and general health of animals, leading to better viability (Rossi et al., 2020).

During the first 10 days of age, T2 promoted the body weight compared to basal diet, and both supplementations with CLP promoted the feed intake with respect to TO (Table 3), however, these production indicators in the following stages remained statistically unchanged ( $p>0.05$ ). It is known that the first days of broilers are the most critical because they have an immature digestive, enzymatic and immune system, being the justification for the use of subtherapeutic antibiotics from the early stages in broilers. Apparently, due to the phytochemical and bactericidal characteristics, CLP exerted a natural growth-promoting effect on these animals. According to Aroche et al. (2018) this natural product (cashew) has antibacterial effects against strains of $E$. coli and $S$. aureus, therefore the supplementation of this phytobiotic can reduce these bacteria in the gastrointestinal tract, which could contribute to better intestinal health of the bird.

Table 4 shows the effect of dietary supplementation with CLP on the carcass traits of broilers at 32 days. T2 increased $(p<0.05)$ carcass and leg yields compared to T0 and T1. However, the breast, abdominal fat, liver, heart, and gizzard yields did not show statistical differences between treatments ( $p>0.05)$. 
Table 4 - Effect of dietary supplementation with cashew leaves powder on broiler carcass characteristics (32 days).

\begin{tabular}{|c|c|c|c|c|c|}
\hline \multirow[b]{2}{*}{ Items (g/kg of BW) } & \multicolumn{3}{|c|}{ Experimental treatments } & \multirow[b]{2}{*}{ SEM \pm} & \multirow[b]{2}{*}{$p$ value } \\
\hline & TO & T1 & $\mathrm{T} 2$ & & \\
\hline Carcass & $66.51^{b}$ & $68.08^{\mathrm{ab}}$ & $69.54^{a}$ & 0.938 & 0.009 \\
\hline Breast & 34.20 & 34.19 & 33.56 & 0.443 & 0.844 \\
\hline Leg & $10.61^{b}$ & $10.55^{b}$ & $11.20^{\mathrm{a}}$ & 0.178 & 0.031 \\
\hline Abdominal fat & 1.15 & 1.00 & 0.99 & 0.091 & 0.397 \\
\hline Liver & 2.13 & 2.08 & 2.02 & 0.070 & 0.531 \\
\hline Heart & 0.60 & 0.62 & 0.63 & 0.026 & 0.682 \\
\hline Gizzard & 1.63 & 1.72 & 1.68 & 0.063 & 0.629 \\
\hline
\end{tabular}

a,bMeans within the same row with different superscript differ significantly $(p<0.05)$.

T0: basal diet (BD); $B D+0.50 \%$ of cashew leaves powder (T1); $B D+0.75 \%$ of cashew leaves powder (T2).

The fact that T2 increases carcass and leg yields showed that this natural product has beneficial chemical characteristics that can increase higher muscle synthesis compared to broilers-control group (Table 4). According to Farag \& El-Rayes (2016), the changes that occur in performance due to the effect of natural products in broiler diets could in turn influence the carcass traits. Likewise, botanicals as dietary supplements can increase the proliferation of some groups of beneficial intestinal microorganisms, which affect the microbial competitive exclusion with a direct impact on the performance and carcass quality (Petracci et al., 2015). Furthermore, the positive effects of the phytogenics on broiler carcass yields have been related to digestibility and absorption of nutrients, mainly amino acids such as lysine, methionine, and threonine (Bess et al., 2012; Azad et al., 2013; Tumbagahon, 2019). The presence of flavonoids, anthocyanidins, and oleamide in the CLP could increase the nutrients digestibility, organic functioning, and antioxidant activity (Martínez et al., 2012c), as well as stimulate the immune system and the secretion of anti-inflammatory cytokines (Kong et al., 2007). Authors as El-Ghousein \& Al-Beitawi (2009), Safamehr et al. (2012), and Mashayekhi et al. (2018) informed an increase of the carcass yield when they used leaves of Thumus valgaris, Urtica dioca and Eucalyptus globulus, as dietary supplemental of broiler diets. However, AlBeitawi \& El-Ghousein (2008) and Vase-Seyyed et al. (2018) with the dietary use of Nigella sativa, Rhus coriaria, Heracleum persicum and Mentha peperita found no changes in the carcass characteristics of broilers, respectively. The aforementioned, determines that, the intakes of leaves powder through the diet in the different feeding phases could generate better use of the nutrients and, therefore, improve the carcass yield; although it will depend on the chemical nature of the secondary metabolites and their concentration in the diet.
Another important fact is that the liver and heart did not increase their relative weight due to the dietary use of CLP (Table 4), similar results were found in a previous study when we used this natural product $(A$. occidentale) up to $1.5 \%$ in pullet diets (Martínez et al., 2013). Meanwhile, Woyengo et al. (2011) reported that diets rich in glucosinolate increased the liver relative weight; however, Molina et al. (2019) found a gradual reduction in the relative weight of this organ in broilers to a higher dietary supplementation with Ganoderma lucidum fungus rich in polysaccharides. Furthermore, Cañete et al. (2017) had related the changes in the heart relative weight with the diarrheal syndrome of birds due to the increased activity of the circulatory system caused by hemoconcentration and hypovolemia, something that did not occur in our experiment. It seems that the secondary metabolites cashew leaves powder had no apparent detrimental effect on these organs because according to Savón et al. (2007) excess phytochemical compounds change the relative weight and functionality of the liver and heart.

Table 5 shows the effect of dietary supplementation up to $0.75 \%$ with cashew leaves powder on the chemical composition and colorimetry of the breast. This natural product (cashew) increased $(p<0.05)$ the ash content and $a^{*}$ and decreased the $L^{*}$ in the breast. However, the moisture, protein, $\mathrm{pH}$, and $b^{*}$ were not statistically different due to the effect of the treatments ( $p>0.05)$.

Previous studies in laying hens found that dietary supplementation with CLP $(0.5 \%)$ improved the external and internal egg quality (Martínez et al., 2012 b), these results show that this phytobiotic can also modify the carcass traits, especially the minerals concentration and red pigments in the breast (Table 5). In this sense, Tumbagahon (2019), found that a natural product derived from cashew, as a phytobiotic additive in broiler diets, improved digestibility, nutrient 
Table 5 - Effect of dietary supplementation with cashew leaves powder on the chemical composition and colorimetry of the broiler breast.

\begin{tabular}{|c|c|c|c|c|c|}
\hline \multirow[b]{2}{*}{ Items } & \multicolumn{3}{|c|}{ Experimental treatments } & \multirow[b]{2}{*}{ SEM \pm} & \multirow[b]{2}{*}{$p$ value } \\
\hline & TO & T1 & $\mathrm{T} 2$ & & \\
\hline Moisture (\%) & 77.37 & 74.84 & 74.62 & 1.126 & 0.213 \\
\hline Protein (\%) & 21.29 & 20.56 & 21.23 & 0.493 & 0.518 \\
\hline Ash (\%) & $0.78^{b}$ & $0.88^{a}$ & $0.99^{a}$ & 0.063 & 0.018 \\
\hline $\mathrm{pH}$ & 5.90 & 5.82 & 5.86 & 0.072 & 0.758 \\
\hline$L^{*}$ & $55.70^{a}$ & $53.94^{b}$ & $54.15^{b}$ & 0.821 & 0.021 \\
\hline$a^{*}$ & $3.06^{\mathrm{b}}$ & $5.34^{a}$ & $5.34^{\mathrm{a}}$ & 0.528 & 0.005 \\
\hline$b^{*}$ & 14.92 & 14.88 & 15.14 & 0371 & 0.866 \\
\hline
\end{tabular}

a,b Means within the same row with different superscript differ significantly $(p<0.05)$.

T0: basal diet (BD); $B D+0.50 \%$ of cashew leaves powder (T1); $B D+0.75 \%$ of cashew leaves powder (T2).

absorption, and meat bromatology. According to table 1 and Martinez et al. (2012 c) cashew leaves are rich sources of electrolytes and trace minerals (such as $\mathrm{Zn}, \mathrm{Co}$ and $\mathrm{Mn}$ ), which have justified their use as a restorative of these minerals in diarrheal syndrome (Cañete et al., 2017). The ash content is directly related to the amount of minerals present in CLP (Table 1), therefore, the treatments with cashew leaves powder (T1 and T2) could have increased the assimilation and translocation of these minerals to the breast, since T1 and T2 increased ash by 0.10 and $0.21 \%$ compared to T0, respectively (Table 5).

According to Martínez et al. (2012 c) cashew leaves powder has anthocyanidins, these secondary metabolites are water-soluble pigments responsible for the red, purple, and blue color in the leaves, flowers, and fruits, which have been attributed anti-inflammatory and antioxidant properties (Khoo et al., 2017). Our previous results reported that the use of this phytobiotic (A. occidentale) in the diets of laying hens increased the pigmentation of the egg yolk (Martínez et al., 2012 b). In accordance, this experiment demonstrated that the dietary use of CLP in broilers also increases the range of red pigments in the breast. According to Wang et al. (2017), the pigmentation of the skin of broilers is achieved through diets that contain pigments that are soluble in lipids or water, which can be transferred to the tissue of animals. Furthermore, the results found have a concordant relationship between $a^{*}$ and $L^{*}$ (Table 5). Grashorn (2016), found that the luminosity $\left(L^{*}\right)$ decreases as the red pigments increase ( $a^{*}$; Table
5). The results show that CLP has the potential as a phytobiotic additive in broiler diets to improve some characteristics of chicken skin, being a purchasing decision factor in some countries (Kennedy et al., 2005).

Dietary supplementation with cashew leaves powder did not change ( $p>0.05)$ the relative weight of the lymphoid organs (Bursa de Fabricius, thymus and spleen) in broilers (Table 6).

Dietary supplementation with CLP was not sufficient to change the relative weight of the lymphoid organs in broilers ( $p>0.05)$, especially bursa of Fabricius and thymus, which are the primary lymphoid organs that involuted from the 60 days of age (Taha-Abdelaziz et al., 2018). These organs participate in the immune response against pathogens through the maturation and differentiation of $\mathrm{B}$ and $\mathrm{T}$ lymphocytes (Lillehoj et al., 2011). Perhaps, these results may be due to the acceptable conditions of tenure, biosecurity and animal welfare of the experiment, since the increased activity and growth of these hematopoietic organs has been related to stressors and the presence of pathogenic bacteria (Lillehoj et al., 2011; Kim \& Lillehoj, 2018). Other results with $0.5 \%$ of cashew leaves powder on pullet diets indicated an increase in the relative weight of the bursa of Fabricius and thymus, however, a higher supplementation provoked a significant reduction in the productive response and in the weight relative of these immune organs related to antinutritional factors (Martínez et al., 2013).

Table 6 - Effect of dietary supplementation of cashew leaves powder on relative weight of the lymphoid organs in broilers.

\begin{tabular}{|c|c|c|c|c|c|}
\hline \multirow[b]{2}{*}{ Items (g/kg of BW) } & \multicolumn{3}{|c|}{ Experimental treatments } & \multirow[b]{2}{*}{ SEM \pm} & \multirow[b]{2}{*}{$p$ value } \\
\hline & TO & $\mathrm{T} 1$ & $\mathrm{~T} 2$ & & \\
\hline Bursa of Fabricius & 0.13 & 0.12 & 0.12 & 0.014 & 0.876 \\
\hline Thymus & 0.14 & 0.14 & 0.14 & 0.010 & 0.922 \\
\hline Spleen & 0.09 & 0.09 & 0.09 & 0.008 & 0.917 \\
\hline
\end{tabular}

T0: basal diet (BD); $B D+0.50 \%$ of cashew leaves powder $(\mathrm{T} 1) ; \mathrm{BD}+0.75 \%$ of cashew leaves powder $(\mathrm{T} 2)$. 
Table 7 shows the effect of dietary supplementation with cashew leaves powder on the count of lactic acid bacteria (LABs) and cecal pH. T1 promoted $(p<0.05)$ the growth of green bacillus with white halo and both treatments with CLP increased $(p<0.05)$ the total cecal lactic acid bacteria. However, no significant differences were observed among treatments $(p>0.05)$ for the irregular white bacilli, irregular white coconuts and cecal $\mathrm{pH}$ in broilers.

The intestinal flora plays a fundamental role in the absorption of nutrients, which improves health and protects the broiler chicken from the appearance of

Table 7 - Effect of dietary supplementation of $A$. occidentale L. leaves powder on lactic acid bacteria count and cecal pH of broilers.

\begin{tabular}{|c|c|c|c|c|c|}
\hline \multirow[b]{2}{*}{ LABs $(\log 10 \text { UFC/g) })^{1}$} & \multicolumn{3}{|c|}{ Experimental treatments } & \multirow[b]{2}{*}{$\mathrm{SEM} \pm$} & \multirow[b]{2}{*}{$P$ value } \\
\hline & TO & T1 & $\mathrm{T} 2$ & & \\
\hline Bacilli2 $^{2}$ & 4.38 & 5.30 & 5.54 & 0.852 & 0.612 \\
\hline Bacilli $^{3}$ & $3.85^{b}$ & $5.19^{a}$ & $4.69^{a b}$ & 0.403 & 0.029 \\
\hline $\mathrm{Cocci}^{4}$ & 5.77 & 5.64 & 5.90 & 0.649 & 0.962 \\
\hline Total LABs & $4.67^{b}$ & $5.38^{a}$ & $5.36^{a}$ & 0.614 & 0.030 \\
\hline Cecal pH & 6.79 & 6.81 & 6.78 & 0.083 & 0.471 \\
\hline
\end{tabular}

a,bMeans within the same row with different superscript differ significantly $(p<0.05)$.

T0: basal diet (BD); BD+0.50\% of cashew leaves powder (T1); BD+0.75\% of cashew leaves powder (T2). LABs: lactic-acid bacteria.

${ }^{1}$ The count was expressed as $\log _{10^{\prime}}$ irregular white colonies; ${ }^{3}$ green colonies with white halo; ${ }^{4}$ white colonies.

enterobacteriaceae (Prado-Rebolledo et al., 2017). Some LABs can regulate the intestinal microflora, given their antagonistic action against specific groups of microorganisms, as well as improve the function of the immune system and intestinal integrity, which is positively correlated with nutritional demand (Xi et al., 2019; Betancur et al., 2020). Clearly, it is observed that the dietary supplementation with CLP improved the growth of the cecal LABs and gut health in broilers, which is related to the higher percentage of viability with $\mathrm{T} 1$, as well as some changes in the carcass traits in the treatments where this natural product was used (Table 3, 4 and 5).

According to Rafeeq et al. (2016) and Giannenas et al. (2018) the use of phytobiotic additives (from Cuminum cyminum L., Foeniculum vulgare Mill. and Achillea wilhemsii C. Koch; Magnifera indica L., Withania somnifera L., Phyllanthus emblica L. and Ocimum sanctum L., respectively), increased the cecal lactic acid bacteria (LABS) count, which improved intestinal permeability and nutrient digestibility. Furthermore, Diaz-Sanchez et al. (2015) reported that, although the action mechanisms of phytobiotics have not been fully elucidated, some authors suggest that these phytochemical compounds stimulate the immune system, specifically by activating lymphocytes, macrophages, and NK cells, in addition to protecting the intestine from the colonization of pathogenic bacteria and promoting bacterial competitive exclusion (Hong et al., 2019). Thus, the use of this natural product could be used in environmentally friendly productions (antibiotic-free), which would contribute to the new demands of consumers.
Although the growth of LABs was higher with CLP, this was not enough to reduce the cecal $\mathrm{pH}$, similar results were found by Martínez et al. (2012a) and Martínez et al. (2013) when they used $0.5 \%$ of CLP on pullet diets. However, Ripon et al. (2019) indicated a proportional decrease in intestinal $\mathrm{pH}$ to higher supplementation of a phytobiotic extract in broiler diets. Also, according to Ding et al. (2011) the phytobiotic products can lower intestinal $\mathrm{pH}$ through the growth of cecal $L A B$ in non-ruminants, with higher emphasis on pigs than in broilers. A higher dietary concentration of cashew leaves powder appears to be necessary to modify the cecal pH in broilers. It is important to note that metabolic disorders, microbial dysbiosis, and high concentration of antinutritional compounds cause an increase in intestinal $\mathrm{pH}$, something that did not occur in this experiment (Latorre et al., 2015). The findings of the present research increase understanding of the positive effects of botanicals products as alternatives to subtherapeutic antibiotics and their beneficial role in the gut microbiota, viability, and carcass traits of broilers.

\section{CONCLUSIONS}

Dietary supplementation with cashew (Anacardium occidentale L.) leaves powder (T2) increased body weight and feed intake up to 10 days of age, after that only viability improved with $\mathrm{T} 1$, without modifying the other productive indicators and the relative weight of the immune organs. Also, the carcass and leg yields increased with $\mathrm{T} 2$ with relation to $\mathrm{TO}$, and this natural product enhanced the ash content, $L^{*}$ and $a^{*}$ in the 
Phytobiotic Effect of Anacardium Occidentale L. Leaves Powder on Performance, Carcass Traits, and Intestinal Characteristics in Broilers breast and the cecal lactic acid bacteria count, no change in the cecal $\mathrm{pH}$.

\section{REFERENCES}

Al-Beitawi N, El-Ghousein SS. Effect of feeding different levels of Nigella sativa seeds (black cumin) on performance, blood constituents and carcass characteristics of broiler chicks. International Journal Poultry Science 2008;7(7):715-721.

AOAC - Association of Official Analytical Chemists. Official methods of analysis. $18^{\text {th }}$ ed. Gaithersburg; 2006.

Aroche R, Martínez Y, Ruan Z, Guan G, Waititu S, Nyachoti CM, et al. Dietary inclusion of a mixed powder of medicinal plant leaves enhances the feed efficiency and immune function in broiler chickens. Journal of Chemistry 2018;(394):1-6

Aviagen. Ross nutrition Sspecifications. 2019 [cited 2020 Jan 11]. Available from: http://es.aviagen.com/assets/Tech_Center/Ross_Broiler/ RossBroilerNutritionSpecs2019-EN.pdf

Awakan OJ, Malomo SO, Adeare AA, Igunnu A, Atolani O, Abeayo AH, et al. Anti-ilammatory and bronchodilatory constituents of leaf extracts of Anacardium occidentale L. in animal models. Journal of Integrative Medicine 2018;16(1):62-70.

Azad MKA, Kikusato M, Zulkifi I, Toyomizu M. Electrolysed reduced water decreases reactive oxygen species-induced oxidative damage to skeletal muscle and improves performance in broiler chickens exposed to medium- term chronic heat stress. British Poultry Science 2013;54(4):503-509

Bess F, Favero A, Vieira SL, Torrent J. The effects of functional oils on broiler diets of varying energy levels. Journal of Applied Poultry Research 2012;21(3):567-578

Betancur C, Martínez Y, Tellez G, Avellaneda C, Velázquez-Martí B. In vitro characterization of indigenous probiotic strains isolated from Colombian creole pigs. Animals 2020;10(1204).

Cañete N, MartínezY, Escalona A, Más D. Antidiarrheal effect of Anacardium occidentale L. leaf powder in neonatal birds. Journal of Animal Production 2017;29(3):47-54.

Diaz-Sanchez S, D'Souza D, Biswas D, Hanning I. Botanical alternatives to antibiotics for use in organic poultry production. Poultry Science 2015;94(6):1419-1430.

Ding $Y Y$, Zhang $\mathrm{CH}$, He X L, Huang L, Yin J. Growth performance responses and indicators of gastrointestinal health in early weaned pigs fed Chinese herbal additives-supplements diets. Journal of Animal Veterinary and Advances 2011;10:1580-1587.

El-Ghousein SS, Al-Beitawi NA. The effect of feeding of crushed thyme (Thymus vulgaris L) on growth, blood constituents, gastrointestinal tract and carcass characteristics of broiler chickens. The Journal of Poultry Science 2009;46(2):100-104.

ECDC- European Centre for Disease Prevention and Control. First joint report on the integrated analysis of the consumption of antimicrobial agents and occurrence of antimicrobial resistance in bacteria from humans and food-producing animals 2015. Solna: ECDC; 2015.

Farag SA, El-Rayes TK. Effect of bee-pollen supplementation on performance, carcass traits and blood parameters of broiler chickens. Asian Journal of Animal and Veterinary Advances 2016;11(3):168-177.

Farias dos Santos GE, Amaral A, Borges da Silva E. Antibacterial activity of irradiated extracts of Anacardium occidentale L. on multiresistant strains of Staphylococcus aureus. Applied Radiation and Isotopes 2018;140:327-332.
Giannenas I, Bonos E, Skoufos I, Tzora A, Stylianaki I, Lazari D, et al. Effect of herbal feed additives on performance parameters, intestinal microbiota, intestinal morphology and meat lipid oxidation of broiler chickens. British Poultry Science 2018;59(5):545-553.

Grashorn M. Feed additives for influencing chicken meat and egg yolk color. In: Handbook on Natural Pigments in Food and Beverages. Sawston: Woodhead Publishing; 2016. p. 283-302.

Hong YH, Yi YS, Han SY, Aziz N, Kim HG, Park SH, et al. Morinda citrifolia noni water extract enhances innate and adaptive immune responses in healthy mice, ex vivo, and in vitro. Phytotherapy Research 2019; 33(3):676-689.

Huang Q, Liu X, Zhao G, Hu T, Wang Y. Potential and challenges of tannins as an alternative to in-feed antibiotics for farm animal production. Animal Nutrition 2017:4(2):137-150.

Kennedy OB, Stewart-Knox BJ, Mitchell PC, Thurnham DI. Flesh colour dominates consumer preference for chicken. Appetite 2005;44(2):181186.

Khoo HE, Azlan A, Tang ST, Lim SM. Anthocyanidins and anthocyanins:colored pigments as food, pharmaceutical ingredients, and the potential health benefits. Food \& Nutrition Research 2017;61(1):1361779.

Kim WH, Lillehoj HS. Immunity, immunomodulation, and antibiotic alternatives to maximize the genetic potential of poultry for growth and disease response. Animal Feed Science and Technology 2018:250:4150.

Kong XF, Wu GY, Liao YP, Hou ZP, Liu HJ, Yin FG, et al. Dietary supplementation with Chinese herbal ultra-fine powder enhances cellular and humoral immunity in early-weaned piglets. Livestock Science 2007;108(1-3):9498.

Latorre JD, Hernandez - Velasco X, Bielke LR, Vicente JL, Wolfenden R, Menconi $A$, et al. Evaluation of a Bacillus direct-fed microbial candidate on digesta viscosity, bacterial translocation, microbiota composition and bone mineralisation in broiler chickens fed on a rye-based diet. British Poultry Science 2015;56(6):723-732.

Lillehoj HS, Kim DK, Bravo DM, Lee SH. Effects of dietary plant-derived phytonutrients on the genome-wide profiles and coccidiosis resistance in the broiler chickens. BMC Proceedings 2011;5 Suppl 4:S34.

Martínez Y, Escalona A, Martínez O, Olmo C, Rodríguez R, Isert M, et al. The use of Anacardium occidentale as nutraceutical in hypoprotein diets for laying hens. Cuban Journal of Agricultural Science 2012b:46(4):395401.

Martínez $Y$, Martínez O, Escalona A, Soto F, Valdivié M. Chemical composition and phytochemical screening of leaf and shoot powder of Anacardium occidentale L. (cashew tree). Cuban Journal of Medicinal Plants 2012c;17(1):1-10.

Martínez Y, Martínez O, Liu G, Ren W, Rodríguez R, Fonseca Y, et al. Effect of dietary supplementation with Anacardium occidentale on growth performance and immune and visceral organ weights in replacement laying pullets. Journal of Food, Agriculture and Environment 2013;13(3\&4):1352-1357.

Martínez Y, Martínez O, Olmos E, Siza S, Betancur C. Nutraceutical effect of Anacardium occidentale in diets of replacement laying pullets. Cordoba MVZ Journal 2012a;17(3):3125-3132.

Martínez $Y$, Soto $F$, Almeida $M$, Hermosilla $R$, Martínez O. Secondary metabolites and in vitro antibacterial activity of extracts from Anacardium occidentale L. (cashew tree). Cuban Journal of Medicinal Plants 2012d;17(4):320-329.

Mashayekhi H, Mazhari M, Esmaeilipou, O. Eucalyptus leaves powder, antibiotic and probiotic addition to broiler diets:effect on growth performance, immune response, blood components and carcass traits. Animal 2018;12(10):2049-2055. 
Martínez Y, Tobar LA, Lagos HM, Parrado CA, Urquía AM, Valdivié M
Silveira-Vasconcelos M da, Gomes-Rochette NF, Oliveira MLM de, NunesPinheiro DCS, Tome AR, Sousa YM de, et al. Anti-inflammatory and wound healing potential of cashew apple juice (Anacardium occidentale L.) in mice. Experimental Biology and Medicine 2015;240(12):16481655

Sunderam $V$, Thiyagarajan $D$, Lawrence AV, Mohammed SSS, Selvaraj A. In-vitro antimicrobial and anticancer properties of green synthesized gold nanoparticles using Anacardium occidentale leaves extract. Saudi Journal of Biological Sciences 2019; 26(3):455-459.

Taha-Abdelaziz K, Hodgins DC, Lammers A, Alkie TN, Sharif S. Effects of early feeding and dietary interventions on development of lymphoid organs and immune competence in neonatal chickens: a review. Veterinary Immunology and Immunopathology 2018;201:1-11.

Tumbagahon NS. Influence of cashew apple (Anacardium occidentale L.) on the stress level, productivity, organoleptic property, and profitability of broiler chickens. Journal of Environmental Treatments Techniques 2019:1165-1174

Vase-Khavari K, Mortezavi SH, Rasouli B, Khusro A, Salem AZ, Seidavi A The effect of three tropical medicinal plants and superzist probiotic on growth performance, carcass characteristics, blood constitutes, immune response, and gut microflora of broiler. Tropical Animal Health and Production 2019; 51(1):33-42.

Wang S, Zhang L, Li J, Cong J, Gao F, Zhou G. Effects of dietary marigold extract supplementation on growth performance, pigmentation, antioxidant capacity and meat quality in broiler chickens. AsianAustralasian Journal of Animal Sciences 2017; 30(1):71-77.

Windisch W, Schedle K, Plitzner C, Kroismayr A. Use of phytogenic products as feed additives for swine and poultry. Journal of Animal Science 2007;86(14 Suppl):140-148.

World Health Organization. Antibiotic resistance. 2018 [cited 10 May 2020]. Available from: https://www.who.int/news-room/fact-sheets/ detail/antibiotic-resistance.

Woyengo TA, Kiarie E, Nyachoti CM. Growth performance, organ weights, and blood parameters of broilers fed diets containing expeller-extracted canola meal. Poultry Science 2011;90:2520-2527.

Xi Y, Shuling N, Kunyuan T, Qiuyang $Z$, Hewen D, ChenCheng $G$, et al. Characteristics of the intestinal flora of specific pathogen free chickens with age. Microbial Pathogenesis 2019;132:325-334. 